\title{
Varietal susceptibility on maize varieties against flour beetles (Tribolium casteneum and Tribolium confusum)
}

\author{
Sabeeta Kumari*, Nasreen Memon, Attaullah Ansari and Bhojoo Mal \\ Department of Zoology, University of Sindh Jamshoro, Sindh-Pakistan \\ *Corresponding author's email: sabitagenious@gmail.com \\ Citation \\ Sabeeta Kumar, Nasreen Memon, Attaullah Ansari and Bhojoo Mal. Varietal susceptibility on maize varieties \\ against flour beetles (Tribolium casteneum and Tribolium confusum). Pure and Applied Biology. Vol. 8, Issue \\ 1, pp304-311. http://dx.doi.org/10.19045/bspab.2018.700189
}

\begin{tabular}{llll}
\hline \hline Received: 20/08/2018 & Revised: 29/10/2018 & Accepted: 10/11/2018 & Online First: 13/11/2018 \\
\hline \hline
\end{tabular}

\section{Abstract}

Maize is commonly known as "C4"and photosynthetic plant. The maize is rich in nutrients such as proteins, carbohydrates, vitamins and fats etc. During research study, it was found that flour beetles including (Tribolium casteneum and Tribolium confusum); both species were causing economic losses on quality and quantity of maize varieties in many areas of Hyderabad, Sindh (Pakistan). Therefore, the experimental study was carried out on susceptibility of maize varieties. Experiments were conducted during the months of Sep 2015 to Aug 2016. During laboratory experiments, the 100g of each variety were put in four jars of $150 \mathrm{~g}$ capacity then ten pairs of both flour beetles introduced in each jar. The culture of both flour beetles was maintained under ambient conditions, $31 \pm 2^{\circ} \mathrm{C}, 27 \pm 5^{\circ} \mathrm{C}, 65 \pm 5 ; 78 \pm 3 \%$ relative humidity and photoperiod with 10 hour light and dark cycle. The percentage of weight loss was taken as criteria for observation of susceptibility on maize varieties against the flour beetles. During this observation; it was found that maximum weight loss occurred on Neelum while minimum on Popcorn variety, $64.87 \mathrm{~g}$ and $5.12 \mathrm{~g}$ respectively. The more susceptibility of Neelum variety was due to softness, seed thickness, seed size and coloration. Statistically, it was proved that consumption on Neelum variety due to both flour beetles have strong positive Pearson correlation with survival of flour beetles under ambient conditions whereas on Popcorn variety consumption had no Pearson correlation with survival of flour beetles. The values are being $r=.834(* *)$ and (a) respectively.

Keywords: Flour beetles; Maize varieties; Susceptible variety; Weight loss

\section{Introduction}

Maize is one of the most important cultivating crops. It is consumed as food for human and animal feed especially in Pakistan, China, India, Japan, and Europe and also used to produce natural substance such as glucose, pharmaceutical oils, medicines, starch and recently for fuel production. Maize is the third growing cereal crop after wheat and rice worldwide, but in Pakistan, it is the fourth largest cultivating crop after cotton, wheat, and rice. The present worldwide corn (Maize) production is about 10.14 billion metric tons [1]. United States is the top most country which is harvesting $(40 \%)$ of worlds overall corn yield, China is the second country for corn harvesting (21\%) and third country for corn harvesting is Brazil (7.9\%). According to this reference [2] the insect pests are the major cause of grain damage in the pantry products. The Flour beetles, T. castaneum and $T$. confusum are causing severe damage on more than hundred stored products such as food meal, dried museum specimens, beans, spices, pasta, flour, cereals, dried flowers, dried cake mix, chocolate, and even nuts, seeds etc the reason is their high reproductive rate [3]. These both species are also important due to their vulnerability to enhance insecticide resistance $[4,5]$. The 
T.casteneum may cause an acute allergic reaction [6]. It is first step to manage this insect pest by observing its susceptibility and remove the basis of the vulnerability [7]. In previous literature, it is found that most of the susceptibility on maize varieties is caused by Maize Weevil (Sitophilus zeamiasis), but in the present study, it was that found most of the susceptibility on each maize variety is caused by flour beetle. So for this reason; the research study was based on the varietal susceptibility on maize varieties against flour beetles. The utilization of the ecologically protected alternatives is the focus of research studies in various laboratories worldwide [8]. Keeping in view, the importance of these problems, the present research was conducted to discuss susceptibility on maize varieties, so the main objective of this study "Varietal susceptibility on maize varieties against flour beetles (Tribolium casteneum and Tribolium confusum)" (Coleoptera: Tenebrionidae).

\section{Materials and methods}

\section{Collection of maize varieties and culture of flour beetles}

Samples (200g) of infested and noninfested maize varieties such as Neelum, White Maize, Kachan, and Popcorn were procured from local market, nearby go downs and warehouses of Hyderabad city (Sindh). The culture of flour beetles was maintained to bring in similar aged flour beetles for the experimental studies. The Maize varieties were cleaned and fresh seeds of each variety were sterilized by keeping in freezer for one week below $0^{\circ} \mathrm{C}$ (for removing the presence of any infestation). Contaminated and diseased grains were removed from each variety. Non-infested seeds were then kept into plastic jars and reared under room conditions for two weeks. The average relative humidity of maize grain was 16 $18 \%$.

\section{Laboratory screening of maize varieties}

The present studies were conducted at the laboratory of pest management, Discipline of Zoology, University of Sindh, Jamshoro during the months of September 2015 to August 2016. Maize varieties were screened for varietal susceptibility against the T. castaneum and T. confusum.

\section{Experimental procedure}

Experiments were conducted during the months of September 2015 to August 2016, at the Entomological laboratory of pest management, Department of Zoology, and University of Sindh Jamshoro. During laboratory experiments, the $100 \mathrm{~g}$ of each maize variety and introduced ten pairs of both flour beetles (male and female) in jars of $150 \mathrm{~g}$ capacity. For this experiment, culture of both flour beetles was maintained under ambient conditions, $31 \pm 2^{\circ} \mathrm{C}$, $27 \pm 5^{\circ} \mathrm{C}, \quad 65 \pm 5, \quad$ and $78 \pm 3 \%$ relative humidity and photoperiod with 10 hour light and dark cycle to increase the population of $T$. castaneum and T.confusum adults. The newly emerged adults kept under observation for experimental purpose. The temperature and relative humidity was recorded daily during the entire period of study. The percentage of weight loss was taken as criteria for assessment of susceptibility on maize varieties against the flour beetles. All varieties were observed regularly at weekly interval. The difference in infestation on each maize variety was observed by susceptibility, grain weight loss (in grams) and seed surface characteristics. The texture characters of each maize variety were observed on an illustration basis. Extra powdery material was sieved out from maize variety and weighted with an electrical balance machine.

Weight loss=weight of damage seed initial weight

The percentage of weight loss was calculated by this formula

$\%$ weight loss $=$ initial weight - weight of damage seed / initial weight* 100 Or Percentage weight losses were observed by the counted and weighed method implemented by Alanko et al. [6].

Percent weight loss $=(\mathrm{Wu} \times \mathrm{Nd})-(\mathrm{Wd} \times$ $\mathrm{Nu}) \times 100 \mathrm{Wu} \times(\mathrm{Nd}+\mathrm{Nu})$ 
Whereas; Weight of undamaged grains $=\mathrm{Wu}$; Number of undamaged grains $=\mathrm{Nu}$; Weight of damaged grains $=W d$; Number of damaged grains $=\mathrm{Nd}$

\section{Data analysis}

The data were analyzed by using (SPSS 20.0 Version) to find out the Pearson correlation between variables (susceptibility and survival of flour beetles) with the effect of temperature and relative humidity.

Results

Susceptibility on different maize varieties against Flour beetles

Susceptibility on Neelum variety against Tribolium castaneum (Herbst, 1797) and Tribolium confusum (Jacquelin du Val, 1868)

The result of the present study indicates the Neelum variety was most affected to flour beetles. The reason was the variation in temperature, humidity, seed size, seed softness and surface thickness. The results showed that Neelum variety was highly susceptible to flour beetles as compared to other varieties. It was found that more weight loss $9.76 \mathrm{~g}$ and $9.08 \mathrm{~g}$ occurs during months of April and June 2016; under ambient conditions $\left(33 \pm 2,27 \pm 2^{\circ} \mathrm{C}, 45 \pm 5\right.$ and $53 \pm 5$ R.H). Hence total weight loss of Neelum variety from the months of Sep 2015 to August 2016 was 64.87g (Table 1). Pearson correlation value of survival of flour beetles on consumption revealed that there was very strong positive and significant Pearson correlation of survival with consumption particularly on Neelum variety (Table 2 ). The values are being $\mathrm{r}=.834(* *)(\mathrm{p}=.001)$.

Table 1. Showing the total weight loss of Neelum variety by Tribolium castaneum and Tribolium confusum

\begin{tabular}{|c|c|c|c|}
\hline Months & Weight loss (in grams) & Temperature $\left({ }^{\circ} \mathbf{C}\right)$ Mean & Humidity (R.H) \\
\hline Sep-15 & $2 \mathrm{~g}$ & 30.255 & 62.24 \\
\hline Oct-15 & $2.4 \mathrm{~g}$ & 29.83 & 54.36 \\
\hline Nov-15 & $2.35 \mathrm{~g}$ & 24.15 & 44.095 \\
\hline Dec-15 & $1.65 \mathrm{~g}$ & 18.205 & 49.6 \\
\hline Jan-16 & $5.11 \mathrm{~g}$ & 18.9 & 59.285 \\
\hline Feb-16 & $6.71 \mathrm{~g}$ & 21.58 & 41.335 \\
\hline Mar-16 & $7.23 \mathrm{~g}$ & 26.82 & 47.625 \\
\hline Apr-16 & $6.79 \mathrm{~g}$ & 30.24 & 46.48 \\
\hline May-16 & $5.12 \mathrm{~g}$ & 33.56 & 56.2 \\
\hline Jun-16 & $9.76 \mathrm{~g}$ & 31.91 & 66 \\
\hline Jul-16 & $6.67 \mathrm{~g}$ & 31.91 & 65.98 \\
\hline Aug-16 & $9.08 \mathrm{~g}$ & 30.6 & 72.835 \\
\hline Total & $\mathbf{6 4 . 8 7 g}$ & & \\
\hline
\end{tabular}

Table 2. The Pearson correlation of the Survival of Tribolium castaneum and Tribolium confusum with the consumption on Neelum Variety

\begin{tabular}{|c|c|c|c|}
\hline \multicolumn{2}{|c|}{ Variables } & Consumption & Survival \\
\hline Consumption & Pearson Correlation & 1 & $.834(* *)$ \\
\hline & Significant & & .001 \\
\hline Survival & Pearson Correlation & $.834(* *)$ & 1 \\
\hline & Significant & .001 & \\
\hline
\end{tabular}

**Correlation is significant at the 0.01 level (2-tailed)

Susceptibility on Kachan variety by Tribolium castaneum and Tribolium confusum
The result of this experiment indicates that Kachan variety was also more affected to flour beetles. The reason was same 
variation in temperature, humidity, seed size, and seed surface also hardness of seed. It was observed that maximum weight loss occurs in the month of July and August 2016 (9.57g and 8.5g); under ambient conditions $\left(30 \pm 2,27 \pm 2{ }^{\circ} \mathrm{C}, 45 \pm 5\right.$ and $53 \pm 5$ R.H). The total weight loss from the month of Sep 2015 to August 2016 was 54.68g
(Table 3 \& Figure 2). Pearson correlation value of survival of flour beetles with consumption particularly on Kachan variety revealed that there was strong positive and significant Pearson correlation of survival with consumption (Table 4). The values are being $\mathrm{r}=.686\left(^{*}\right)(\mathrm{p}=.014)$.

Table 3. Showing the total weight loss on Kachan variety by Tribolium castaneum and Tribolium confusum

\begin{tabular}{|c|c|c|c|}
\hline Months & Weight loss & \multicolumn{2}{|c|}{ Temperature \& Humidity(Mean) } \\
\hline Sep-15 & $3.05 \mathrm{~g}$ & 30.25 & $\mathbf{6 2 . 2 4}$ \\
\hline Oct-15 & $1.2 \mathrm{~g}$ & 29.83 & $\mathbf{5 4 . 3 6}$ \\
\hline Nov-15 & $2.55 \mathrm{~g}$ & 24.15 & $\mathbf{4 4 . 0 9 5}$ \\
\hline Dec-15 & $2.46 \mathrm{~g}$ & 18.205 & $\mathbf{4 9 . 6}$ \\
\hline Jan-16 & $6.68 \mathrm{~g}$ & 18.9 & $\mathbf{5 9 . 2 8 5}$ \\
\hline Feb-16 & $5.69 \mathrm{~g}$ & 21.58 & $\mathbf{4 1 . 3 3 5}$ \\
\hline Mar-16 & $2.46 \mathrm{~g}$ & 26.82 & $\mathbf{4 7 . 6 2 5}$ \\
\hline Apr-16 & $3.61 \mathrm{~g}$ & 30.24 & $\mathbf{4 6 . 4 8}$ \\
\hline May-16 & $2.82 \mathrm{~g}$ & 33.56 & $\mathbf{5 6 . 2}$ \\
\hline Jun-16 & $6.09 \mathrm{~g}$ & 31.91 & $\mathbf{6 6}$ \\
\hline Jul-16 & $9.57 \mathrm{~g}$ & 31.91 & $\mathbf{6 5 . 9 8}$ \\
\hline Aug-16 & $8.5 \mathrm{~g}$ & 30.6 & $\mathbf{7 2 . 8 3 5}$ \\
\hline Total & $\mathbf{5 4 . 6 8 g}$ & & \\
\hline
\end{tabular}

Table 4. The Pearson correlation of the Survival of the flour beetles with consumption on Kachan Variety

\begin{tabular}{|c|c|c|c|}
\hline \multicolumn{2}{|c|}{ Variables } & Consumption & Survival \\
\hline Consumption & Pearson Correlation & 1 & $.686\left(^{*}\right)$ \\
\hline & Significant & & .014 \\
\hline Survival & Pearson Correlation & $.686\left(^{*}\right)$ & 1 \\
\hline & Significant & .014 & \\
\hline
\end{tabular}

*Correlation is significant at the 0.05 level (2-tailed)

Susceptibility on Popcorn variety by Tribolium castaneum and Tribolium confusum

In (Table 5) shows that popcorn variety was most resistant variety of maize. It is observed that the resistance of this variety was due to the grain hardness and small seed size, variation in temperature and relative humidity also thickness of popcorn variety, which may affect the process of oviposition in Popcorn seeds. The present study showed that increasing hardness, size and thickness of seed resulted in reducing the consumption or susceptibility of popcorn. Pearson coefficient value of consumption on survival revealed that there was a weak and significant correlation of consumption on survival $\mathrm{r}=.337(\mathrm{p}=.283)$, whereas the survival had negative correlation with consumption on Popcorn variety. The value being $r=a$ ("a" Cannot be computed because at least one of the variables is constant). Moreover the values of temperature were found negative Pearson correlation with the consumption that has $r=1(p=.283)$. This was significant of humidity with consumption (Table 6). 
Table 5. Showing the total weight loss on Popcorn variety by Tribolium castaneum and Tribolium confusum

\begin{tabular}{|c|c|c|c|}
\hline Months & Weight loss & \multicolumn{2}{|c|}{ Temperature \&Humidity(Mean) } \\
\hline Sep-15 & $0.15 \mathrm{~g}$ & 30.255 & 62.24 \\
\hline Oct-15 & $0.5 \mathrm{~g}$ & 29.83 & 54.36 \\
\hline Nov-15 & $0.15 \mathrm{~g}$ & 24.15 & 44.095 \\
\hline Dec-15 & $0.7 \mathrm{~g}$ & 18.205 & 49.6 \\
\hline Jan-16 & $0.8 \mathrm{~g}$ & 18.9 & 59.285 \\
\hline Feb-16 & $0.26 \mathrm{~g}$ & 21.58 & 41.335 \\
\hline Mar-16 & $0.16 \mathrm{~g}$ & 26.82 & 47.625 \\
\hline Apr-16 & $0.5 \mathrm{~g}$ & 30.24 & 46.48 \\
\hline May-16 & $0.96 \mathrm{~g}$ & 33.56 & 56.2 \\
\hline Jun-16 & $0.94 \mathrm{~g}$ & 31.91 & 65 \\
\hline Jul-16 & $0.94 \mathrm{~g}$ & 31.91 & 72.835 \\
\hline Aug-16 & $0.94 \mathrm{~g}$ & 30.6 & \\
\hline Total & $\mathbf{5 . 1 2 g}$ & & \\
\hline
\end{tabular}

Table 6. The Pearson correlation of the survival of flour beetles with consumption on popcorn variety

\begin{tabular}{|c|c|c|c|}
\hline \multicolumn{2}{|c|}{ Variables } & Survival & Consumption \\
\hline Survival & Pearson Correlation & .(a) & .(a) \\
\hline & Significant & & . \\
\hline Consumption & Pearson Correlation & .(a) & 1 \\
\hline & Significant & & \\
\hline
\end{tabular}

Note: "a" Cannot be computed because at least one of the variables is constant

\section{Susceptibility on White maize variety by Tribolium castaneum and Tribolium confusuma}

The result of the study indicates that white maize variety was moderately resistant variety of maize. It was observed that the resistance of this variance was due to the grain resistance and seed size, variation in temperature and relative humidity also thickness of White maize, which may affect the process of oviposition in White maizeseeds. The present study showed that increasing size and thickness of seed resulted in reducing the consumption or susceptibility on white maize variety (Table 7). Pearson correlation value of survival of flour beetles with consumption revealed that there was a weak and significant correlation of survival with consumption on White maize variety (Table 8 ). The value being $\mathrm{r}=.422(\mathrm{p}=.172)$. Moreover the values of temperature were found negative Pearson correlation with the consumption that has $\mathrm{r}=.337(\mathrm{p}=.283)$.

\section{Discussion}

Our present studies revealed that under ambient conditions $\left(31 \pm 2^{\circ} \mathrm{C}, 27 \pm 5^{\circ} \mathrm{C} ; 65 \pm 5\right.$ and $78 \pm 3 \%$ ) relative humidity and photoperiod with 10 hour light and dark cycle. It was observed that susceptibility; percentage of weight loss; seed damage; and oviposition was high on Neelum and Kachan variety but least on Popcorn maize variety by Tribolium castaneum and Tribolium confusum. The another reason of high susceptibility on Neelum as well on Kachan variety was due to the softness of seed coat, thickness and colorations also chemical composition. These results clearly indicated that the adult progeny, feeding behavior, seed damage and weight loss of maize varieties caused by Tribolium Spp individually as well as in combination varied significantly. It was monitored that different moisture contents are responsible to increase the susceptibility on different maize varieties against both flour beetles. 
Table 7. Showing the total weight loss of White maize against Tribolium castaneum and Tribolium confusum

\begin{tabular}{|c|c|c|c|}
\hline Months & Weight loss & Temp (Mean) ${ }^{\mathbf{}} \mathbf{C}$ & Humidity (Mean) R.H \\
\hline Sep-15 & $1.05 \mathrm{~g}$ & 30.255 & 62.24 \\
\hline Oct-15 & $1.25 \mathrm{~g}$ & 29.83 & 54.36 \\
\hline Nov-15 & $1.15 \mathrm{~g}$ & 24.15 & 44.095 \\
\hline Dec-15 & $1.25 \mathrm{~g}$ & 18.205 & 49.6 \\
\hline Jan-16 & $0.22 \mathrm{~g}$ & 18.9 & 59.285 \\
\hline Feb-16 & $1.54 \mathrm{~g}$ & 21.58 & 41.335 \\
\hline Mar-16 & $2.92 \mathrm{~g}$ & 26.82 & 47.625 \\
\hline Apr-16 & $1.38 \mathrm{~g}$ & 30.24 & 46.48 \\
\hline May-16 & $1.4 \mathrm{~g}$ & 33.56 & 56.2 \\
\hline Jun-16 & $2.5 \mathrm{~g}$ & 31.91 & 66 \\
\hline Jul-16 & $1.2 \mathrm{~g}$ & 31.91 & 65.98 \\
\hline Aug-16 & $1.52 \mathrm{~g}$ & 30.6 & 72.835 \\
\hline Total & $\mathbf{1 7 . 3 8 g}$ & & \\
\hline
\end{tabular}

Table 8. The Pearson correlation of survival of flour beetles with consumption on white maize variety

\begin{tabular}{|c|c|c|c|}
\hline \multicolumn{2}{|c|}{ Variables } & Consumption & Survival \\
\hline Consumption & Pearson Correlation & 1 & .422 \\
\hline & Significant & & .172 \\
\hline Survival & Pearson Correlation & .422 & 1 \\
\hline & Significant & .172 & \\
\hline
\end{tabular}

This result was agreed with reference [9] reported that moisture contents and warmer climate increases within pantry products are main indicators of the survival of fungus and arthropods (insects). Using infestation tables and comparing the results with that of the control varieties, except Popcorn other varieties showed susceptibility to Red flour beetles and Confused flour beetles. This result was compared with [10] stated that moisture content over 16 percent renders resistant maize genotypes susceptibility. During storage condition moisture tends to increase within the cereal products and increase the moisture substances. This could describe the decrease in resistance on some of the varieties. In many localities of Hyderabad, Sindh (Pakistan), it was observed that most of the infestation/ susceptibility on pantry products especially on maize varieties caused by Tribolium casteneum and Tribolium confusum, but this result was varied with [11, 12] because in preceding review literature it was found that most of the financial harm on storage maize varieties caused by maize weevil, confused flour beetle, lesser grain weevil, dried bean beetle, larger grain borer, Prosteph anustruncates, and red flour beetle, etc. From the above mentioned statements; the present studies revealed that; to control susceptibility on different maize varieties, cultivars must cultivate resistant varieties against any kind of pest. It is one of the important methods to decrease the susceptibility and oviposition process also to reduce the population growth rate against any pest. Our present findings revealed that greater susceptibility occurs on Neelum and Kachan varieties during months of June, July and August 2016. It was also observed that physical and biological factors such as temperature, relative humidity, insects, and micro-organisms had positive effect on the susceptibility of maize varieties. According to [13] who investigated the response of above factors are grouped into physical 
(light, temperature and relative humidity), biological (insect pest, fungi, rodent sand birds), and men made engineering tools (instruments of storage places and managing equipment). All these factors directly or indirectly effect on susceptibility on stored products.

It was found that, in many areas of Sindh (Pakistan); maize varieties were mostly susceptible to flour beetles ( $T$. casteneum and $T$. confusum), but our results were little bit varied with [14], according to this reference common insect pests on maize varieties are maize weevils (Sitophilus zeamais), African bollworm, African armyworm, cutworms, larger grain borer, red flour beetle, dried bean beetles and Indian moths. Finally, under favorable conditions; it is observed that the rate of consumption, the rate of susceptibility; oviposition process was high on Neelum variety as compared to other maize varieties. It can be suggested that by growing tolerant varieties, the susceptibility can be controlled/limited by flour beetle.

\section{Conclusions}

The present study was conducted from September 2015 to August 2016 in laboratory. Experiments were conducted at the Entomology Laboratory, Department of Zoology and University of Sindh Jamshoro. Four commonly used varieties were selected Kachan, Popcorn, Neelum, and White maize for the observation of susceptibility on maize varieties against flour beetles under ambient conditions. It was observed that Neelum variety was the most favorable food for both flour beetles and Popcorn was the least favorable food for decreasing the susceptibility, growth and development of different stages of both flour beetles. It was observed that resistance of this variety was due to the kernel hardness which may not have negative effect of oviposition on Popcorn variety, but also had positive effect of oviposition on Neelum variety. In present study, it was concluded that seed coat thickness resulted in decreased susceptibility. The results of comparative susceptibility experiment clearly revealed that Neelum variety was significantly susceptible to flour beetles while Popcorn variety was comparatively resistant to flour beetles attack. It was observed that maximum consumption was on Neelum variety while minimum on Popcorn, $(64.87 \mathrm{~g})$ and $(5.12 \mathrm{~g})$ respectively. Statistically, it was proved that consumption on Neelum variety due to both flour beetles have strong positive Pearson correlation with survival of flour beetles under ambient conditions whereas on Popcorn variety consumption had no Pearson correlation with survival of flour beetles. The values being $r=.834(* *)$ and (a) respectively.

\section{Author's contributions}

Conceived and designed the experiments: $\mathrm{K}$ Sabeeta, N Memon\& MA Shah, Performed the experiments: K Sabeeta, Analyzed the data: K Sabeeta\& N Memon, Contributed reagents/ materials/ analysis tools: $\mathrm{K}$ Sabeeta \& B Mal, Wrote the paper: K Sabeeta \& N Memon.

\section{Acknowledgement}

Author is highly grateful to the Higher Education Commission for providing such platform to promote our research based studies.

\section{References}

1. Acharya V \& Young B (2008). A review of the potential of bio-ethanol in New Zealand. Bull of Sci Technol Society 28: 143-148.

2. De Groote H, Dema G, Sonda GB \& Gitonga ZM (2013). Maize for food and feed in East Africa-the farmers' perspective. Field Crops Res 153: 2236.

3. Weston PA \&Rattlingourd PL (2000). Progeny production by Tribolium castaneum (Coleoptera: Tenebrionidae) and Oryzaephilus surinamensis (Coleoptera: Silvanidae) on maize previously infested by Sitotrogacerealla (Lepidoptera: Gelechiidae). $J$ of Economic Entomol 93: 533-536. 
4. Koehler PG (April 2003). Pantry and Stored Food Pests: EDIS, http://edis.ifas.ufl.edu/IG095.

5. Shazali MEH (1987). Problems of food grain storage in the Sudan with particular reference to insects. Workshop on storage and preservation on food grains. Khartoum, Sudan.

6. Alanko K., Tuomi Y et al (2000). Occupational IgE-mediated allergy to Tribolium confusum (confused flour beetle). Allergy 55: 879-882.

7. Suleiman R, Rosentrater K \& Bern C (2013). Effects of Deterioration Parameters on Storage of Maize: A Review. J of Natural Sci Res 3(9): 147165.

8. Shazali MEH \& Smith RH (1990). The growth of single and mixed laboratory populations of three insect's pests in stored sorghum. Bull of Grain Techno. 28(2): 107-112.

9. Sparks TH \& Yates TJ (1997). The effect of spring temperature on the appearance dates of shoot flies, 18831993. Ecography 20: 368-374.

10. Hassan M \& Khan AR (1988). Growth and development of the red flour beetle, Tribolium castaneum Herbst, on red lentil flour, Lensesculenta. Bangla J of Zool 16(2): 177-180.

11. Good NE (1936). The flour beetles of the genus Tribolium. UDSA Technical Bulletin 498:1-57.

12. Ryan MF, Park T \& Mertz DB (1970). Flour beetles: response to extract of their own pupae. Sci 170: 178-180.

13. Silhacek D \& Murphy C (2006). A simple wheat germ diet for studying the nutrient requirements of the Indian meal moth, Poldiaunter punctella $(\mathrm{H})$. J of Stored Products Res 42: 427-437.

14. Via S (1999). Cannibalism facilitates the use of a novel environment in the flour beetle, Tribolium castaneum. Heredity 82: 267-275. 